\title{
MEETINGS AND ANNOUNCEMENTS
}

\section{PAN REGIONAL CONFERENCE OF THE INTERNATIONAL HOSPITAL FEDERATION CONFERENCE ANNOUNCEMENT AND CALL FOR PAPERS}

The Pan Regional Conference of the International Hospital Federation, under the auspices of the Hospital Committee of the European Community, will be held in Jerusalem, Israel, on October 14-19, 1990.

Topics to be addressed include the following: hospitals and society, psychology and architecture in planning hospitals, the hospital of the future, management of hospitals, planning for an aging population, psychiatric hospitals, field hospitals, primary nursing, outpatient clinics, and hospital maintenance.

Registration fees will be US $\$ 220$ for IHF members and US $\$ 260$ for nonmembers until August 15, 1990. After August 15, registration fees will be US $\$ 290$ for members and US $\$ 340$ for nonmembers.

Abstracts of 200 words may be submitted on a form provided in the conference announcement and must be received by May 30, 1990. For more information, abstract forms, and registration materials, please contact: The Secretariat, Pan Regional Conference of the International Hospital Federation, P.O. Box 50006, Tel Aviv 61500, Israel. (Tel) 9723 654571, (Telex) 341171 KENS IL, (Fax) 9723655674.

\section{ABSTRACTS AVAILABLE FROM THE FIFTH ANNUAL MEETING OF THE INTERNATIONAL SOCIETY OF TECHNOLOGY ASSESSMENT IN HEALTH CARE}

Abstracts from the Fifth Annual Meeting of the International Society of Technology Assessment in Health Care held in London on June 5-6, 1989, are available for $£ 4.00$ plus $10 \%$ for postage and packing, from Bailey Distribution Limited, Department D/KFP, Warner House, Bowles Well Gardens, West Bay Road, Folkestone, Kent CT19 6PH, England. Checks should be made out to Bailey Distribution Ltd.

They are also available over the counter at the King's Fund Centre for Health Services Development, 126 Albert Street, London, NW1 7NF, England. (Tel) 71-267-6111. 